\title{
Das Prinzip der Selbstverantwortung
}

\section{Grundlagen und Bedeutung im heutigen Privatrecht}

Hrsg. v. Karl Riesenhuber

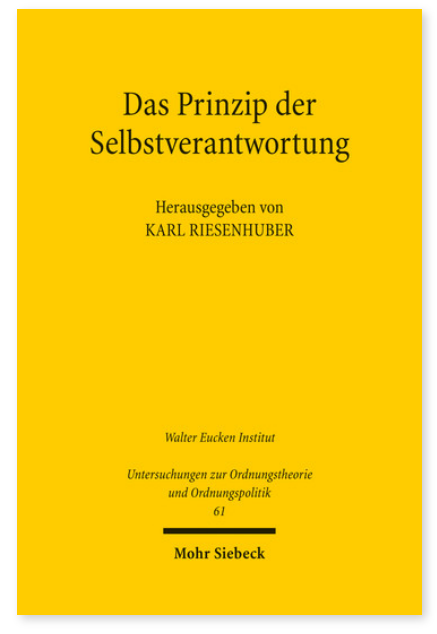

2011; unveränderte Studienausgabe; 2012. XXII, 526 Seiten. UOrd 61

ISBN 978-3-16-151873-7

DOI 10.1628/978-3-16-151873-7

eBook PDF 79,00€

ISBN 978-3-16-151805-8

fadengeheftete Broschur 79,00€
Ob Finanzkrise, Europäische Rechtsangleichung, Verbraucherschutz oder Scheidungsfolgen: Selbstverantwortung, das Gegenstück der individuellen Freiheit, ist ein fundamentales Prinzip unserer (Privat-) Rechtsordnung. Indes wird ihr zumeist wenig Aufmerksamkeit geschenkt. Das mag seinen Grund darin haben, dass man lieber das Süße als das Bittere betont, auch wenn beides untrennbar miteinander verbunden ist. Ein anderer Grund mag aber (laut v. Hayek) darin liegen, dass die Wertschätzung für die Freiheit gesunken ist.

Inhaltsübersicht

Karl Riesenhuber: Das Prinzip der Selbstverantwortung. Grundlagen und Bedeutung im heutigen Privatrecht

\section{Grundlagen}

Jan Dirk Harke: Das Prinzip der Selbstverantwortung im römischen Recht - Martin Metzler: Diskussionsbericht - Viktor Vanberg: Freiheit und Verantwortung. Neurowissenschaftliche Erkenntnisse und ordnungsökonomische Folgerungen Wolfgang Prinz: Selbstverantwortung aus der Sicht der Kognitionswissenschaften - Alexander Roos: Diskussionsbericht Matthias Leistner: Der Grundsatz der Selbstverantwortung. Verhaltensökonomische Grundlagen - Uta Wilkens/Daniel Nermerich: Der Grundsatz der Selbstverantwortung in der verhaltenswissenschaftlichen Organisations- und Führungsforschung - Sven Lohse: Diskussionsbericht - Peter-Christian Müller-Graff: Der Grundsatz der Selbstverantwortung im heutigen Privatrecht. Europarechtliche Grundlagen - Frank Rosenkranz: Diskussionsbericht - Christian Hillgruber: Der Grundsatz der Selbstverantwortung. Verfassungsrechtliche Grundlagen und Grenzen - Jörg Neuner: Der Grundsatz der Selbstverantwortung und das Sozialstaatsprinzip - Sina Krefft: Diskussionsbericht

\section{Dogmatik}

Karl Riesenhuber: Der Grundsatz der Selbstverantwortung im Europäischen Privatrecht - Michael Martinek: Der Grundsatz der Selbstverantwortung im Vertrags- und Verbraucherrecht - Athina Papikinou: Diskussionsbericht - Renate Schaub: Das Prinzip der Selbstverantwortung im Deliktsrecht - Barbara Dauner-Lieb: Der Grundsatz der Selbstverantwortung im Familienrecht. Dargestellt am Beispiel der Gütertrennung - Ulrike Koch: Diskussionsbericht - Volker Rieble: Selbstverantwortung im Arbeitsrecht - Susanne Kalss: Selbstverantwortung im Gesellschaftsrecht - Frank Rosenkranz: Diskussionsbericht - Alexander Peukert: Der Grundsatz der Selbstverantwortung im Lauterkeitsrecht - Christian Hofmann: Das Prinzip der Selbstverantwortung im Bank- und Kapitalmarktrecht - Sarah Rohde: Diskussionsbericht - Peter A. Windel: Der Grundsatz der Selbstverantwortung und das Insolvenzrecht - Günter Hager: Selbstverantwortung in rechtsvergleichender Sicht - Christof Taube: Diskussionsbericht

Karl Riesenhuber ist Inhaber des Lehrstuhls für Bürgerliches Recht, Deutsches und Europäisches Handels- und Wirtschaftsrecht an der Ruhr-Universität Bochum.

Jetzt bestellen:

https://mohrsiebeck.com/buch/das-prinzip-der-selbstverantwortung-9783161518737?no_cache=1

order@mohrsiebeck.com

Telefon: +49 (0)7071-923-17

Telefax: $+49(0) 7071-51104$ 